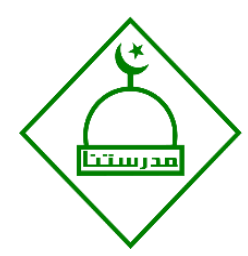

\title{
Analisis model pembelajaran kooperatif tipe jigsaw terhadap hasil belajar siswa sekolah dasar
}

\author{
Teten Ginanjar Rahayu1, Rahman², Rizal Saepulloh Herawan ${ }^{3}$, Adi Pauji Pitriadi ${ }^{4}$, \\ Anggy Giri Prawiyogi ${ }^{5}$ \\ ${ }^{1}$ Program Studi Pendidikan Dasar Universitas Pendidikan Indonesia, ${ }^{2}$ Universitas Pendidikan \\ Indonesia, ${ }^{3}$ Program Studi Pendidikan Dasar Universitas Pendidikan Indonesia, ${ }^{4}$ Program Studi \\ Pendidikan Dasar Universitas Penddikan Indonesia, ${ }^{5}$ Universitas Buana Perjuangan Karawang \\ ${ }^{1}$ teten.ginanjar.r@student.upi.edu, ${ }^{2}$ rahmanprofupi@upi.edu, \\ rrizalsaepullohherawan0@gmail.com, ${ }^{3}$ adipauji@24gmail.com, \\ 5anggy.prawiyogi@ubpkarawang.ac.id
}

\begin{abstract}
ABSTRAK
Pembelajaran Kooperatif Tipe Jigsaw yang dilakukan oleh guru sekolah dasar pada mata pelajaran IPS, Matematika, IPA, dan PKN. Metode pengumpulan data yang digunakan dalam penelitian ini adalah studi literatur. Jenis data dalam penelitian ini merupakan artikel-artikel hasil penelitian yang dilakukan oleh guru sekolah dasar berkaitan dengan implementasi Model Pembelajaran Kooperatif Tipe Jigsaw terhadap hasil belajar siswa sekolah dasar pada mata pelajaran IPS, Matematika, IPA, dan PKN. Adapun artikel hasil penelitian yang dijadikan merupakan artikel hasil penelitian yang terbit pada tahun 2015 sampai dengan tahun 2020. Dari hasil analisis yang dilakukan ditemukan bahwa model pembelajaran Kooperatif Learning Tipe Jigsaw dapat meningkatkan hasil pembelajaran siswa dalam pembelajaran IPS, Matematika, IPA, dan PKN. Sehingga diperoleh kesimpulan bahwa penggunaan model pembelajaran Kooperatif Tipe Jigsaw efektif untuk meningkatkan hasil belajar siswa di sekolah dasar pada pembelajaran IPS, Matematika, IPA, dan PKN.
\end{abstract}

Keywords: Pembelajaran Kooperatif, Tipe Jigsaw, Hasil Belajar, pembelajaran IPS, pembelajaran Matematika, pembelajaran IPA, pembelajaran PKN.

\section{Analysis of the implementation of the jigsaw type cooperative learning model in improving student learning outcomes in elementary schools}

\begin{abstract}
The purpose of this study was to determine the implementation of the Jigsaw Type Cooperative Learning Model carried out by elementary school teachers in the subjects of Social Sciences, Mathematics, Natural Sciences, and Civics. The data collection method used in this research is a literature study. The type of data in this study is the articles of research conducted by elementary school teachers related to the implementation of the Jigsaw Type of Cooperative Learning Model on learning outcomes of elementary school students in the subjects of Social Sciences, Mathematics, Science, and Civics. The research articles are used as research articles published from 2015 to 2020. From the results of the analysis conducted, it was found that the Jigsaw Type of Cooperative Learning model can improve student learning outcomes in social studies, mathematics, science, and civics learning. So it can be concluded that the use of the Jigsaw Type Cooperative learning model is effective for improving student learning outcomes in elementary schools in social studies, mathematics, science, and civics learning.
\end{abstract}


Keywords: Cooperative Learning, Jigsaw Type, Learning Outcomes, Social Studies learning, Mathematics learning, Science learning, Civics learning.

\section{PENDAHULUAN}

Dalam menjalankan proses pembelajaran, guru harus melibatkan siswa agar aktif dalam pembelajaran. Melibatkan siswa dalam proses pembelajaran akan mengembangkan semua potensi kecerdasan siswa. Sehingga bukan hanya aspek kecerdasan kogtinifnya saja yang terlatih dan berkembang. Aspek yang lain seperti aspek kecerdasan sosial, emosional dan spiritualnnya juga harus dikembangkan dengan baik. Hal ini sejalan dengan pendapat Kristin (2018) yang mengemukakan bahwa "Proses pembelajaran yang baik dan tepat mempengaruhi kualitas pembelajaran. Dalam rangka meningkatkan mutu pendidikan yang bagus harapan yang ingin dicapai adalah pembelajar memahami apa yang dipelajari dan dapat diterapkan di kehidupan yang nyata. Oleh karena itu, guru dituntut memiliki pengetahuan yang inovatif agar dalam proses pembelajaran bukan hanya guru yang aktif tetapi juga siswanya. Dengan demikian proses pembelajaran yang optimal akan terwujud." Pendapat tersebut menyatakanbahwa pembelajaran itu harus melibatkan siswa. Sehingga pembelajar memahami apa yang dipelajari dan dapat diterapkan di kehidupan yang nyata.

Apabila ada siswa yang kurang bahkan tidak faham terhadap materi yang telah dipelajari, maka hal tersebut akan menjadi sebuah permasalahan yang harus dicari inti permasalahnnya dan dicari solusinya. Dalam hal ini, dalam melaksanakan proses pembelajaran menjadi penting untuk dievaluasi kembali. Apakah dalam proses pembelajarannya sudah baik dan maksimal atau belum. Sejalan dengan pendapat Kristin (2016: 91) yang mengatakan bahwa proses pembelajaran dapat berlangsung karena adanya siswa, guru, kurikulum, satu dengan yang lain saling terkait atau saling berhubungan. Siswa dapat belajar dengan baik jika sarana dan prasarana untuk belajar memadai, model pembelajaran guru menarik, siswa ikut aktif dalam proses pembelajaran sehingga siswa tidak merasa jenuh atau bosan ketika mengikuti pembelajaran di kelas." Berdasarkan pendapat tersebut, proses pembelajaran harus dijalankan dengan baik agar siswa tidak merasa jenuh atau bosan dalam mengikuti pembelajaran. Untuk itu, guru harus memiliki keterampilan dan kreatifitas dalam menentukan model pembelajaran agar proses pembelajran berjalan dengan baik, sehingga akan mendapatkan hasil belajar yang baik pula.

Salah satu model pembelajaran yang dapat digunakan untuk membantu guru dalam proses pembelajaran adalah Model Pembelajaran Kooperatif Tipe Jigsaw. Model Pembelajaran Kooperatif Tipe Jigsaw merupakan salah satu model yang dapat diterapkan dalam proses pembelajaran di dalam kelas karena model ini menarik bagi siswa. Mereka dapat melakukan hal 
yang tidak membosankan sekaligus dapat melatih semua aspek kecerdasan yang mereka miliki. Model Pembelajaran Kooperatif merupakan model pembelajaran yang mengkondisikan siswa untuk dapat melakukan kerjasama, bertanggungjawab, berkolaborasi, dan berdiskusi dengan teman-teman sekelasnya. Hal ini sejalan dengan pendapat Huda (2014) bahwa “ Dalam jigsaw, guru harus memahami kemampuan dan pengalaman siswa dan membantu siswa dan membantu siswa mengaktifkan skema ini agar materi pelajaran menjadi lebih bermakna. Guru juga memberi banyak kesempatan kepada siswa untuk mengolah informasi dan meningkatkan keterampilan berkomunikasi." Selain itu, menurut Nurdyansyah (2016) menjelaskan bahwa "Pembelajaran kooperatif model Jigsaw ini mengambil pola cara bekerja sebuah gergaji (zigzag), yaitu siswa melakukan suatu kegiatan belajar dengan cara bekerja sama dengan siswa lain untuk mencapai tujuan bersama." Sementara menurut Huda (2014) tentang Model Pembelajaran Kooperatif Tipe Jigsaw ini mengemukakan bahwa "Guru juga harus memberi banyak kesempatan pada siswa untuk mengolah informasi dan meningkatkan keterampilan berkomunikasi”. Jadi, dengan menerapkan model pembelajaran ini akan melatih siswa memiliki keterampilan bekerjasama, berkolaborasi, bertanggungjawab, dan menguasai materi.

Menurut Rahman (2019) langkah-langkah melaksanakan Model Pembelajaran Kooperatif Tipe Jigsaw adalah sebagai berikut: Guru mengelompokkan murid ke dalam empat anggota tim; setiap anggota dalam tim diberi bagian materi pembelajaran yang berbeda; Setiap angota tim menerima materi pembelajaran atau tugas; anggota dari tim yang berbeda yang telah mempelajari materi pembelajaran yang sama bertemu dalam kelompok baru (kelompok ahli) untuk mendiskusikan materi pembelajaran; setelah berdiskusi sebagai tim ahli dari setiap anggota kembali ke kelompok asal dan bergantian mengajar teman satu tim mereka tentang bahan pembelajaran yang mereka kuasai dan tiap anggota lainnya mendengarkan; setiap tim ahli mempresentasikan hasil diskusi di hadapan kelas; dan guru mengevaluasi.

Sementara menurut Huda (2014) langkah-langkah melaksanakan Model Pembelajaran Kooperatif Tipe Jigsaw adalah, siswa dibagi dalam kelompok berempat, bagian/subtopik pertama diberikan pada siswa/anggota 1, sedangkan siswa/anggota 2 menerima bagian/subtopik yang kedua. Demikian seterusnya, kemudian, siswa diminta membaca/mengerjakan bagian/subtopik mereka masing-masing, setelah selesai, siswa saling berdiskusi mengenaik bagian/subtopik yang dibaca/dikerjakan masing-masing bersama rekan-rekan satu anggotanya. Dalam kegiatan ini, siswa bisa saling melengkapi dan berinteraksi antara satu dengan yang lainnya. Khusus untuk kegiatan membaca, guru dapat membagi bagian-bagian sebuah cerita yang belum utuh kepada masingmasing siswa. Siswa membaca bagian-bagian tersebut untuk meprediksikan apa yang dikisahkan 
dalam cerita tersebut. Kegiatan ini bisa diakhiri dengan diskusi mengenai topik tersebut. Diskusi ini bisa dilakukan antarkelompok atau bersama seluruh siswa.

Berdasarkan uraian tersebut, maka fokus penelitian ini yaitu penggunaan model pembelajatan kooperatif tipe jigsaw dapat meningkatkan hasil bejar IPS, IPA, PKN, Matematika pada pembelajaran di Sekolah Dasar.

\section{METODE PENELITIAN}

Metode penelitian ini menggunakan jenis penelitian Studi Literatur. Pengumpulan dan penelusuran data dilakukan dengan menelusuri Google Scholar. Menurut Sari (2020) dalam Melinda (2020) mengemukakan bahwa "Studi literatur merupakan aktivitas penelitian yang dilaksanakan menggunakan teknik pengumpulan informasi dan data dengan kontribusi bermacam-macam alat penunjang yang terdapat di perpustakaan seperti buku referensi, hasil penelitian serupa yang telah dilakukan sebelumnya, artikel, catatan, serta berbagai jurnal yang bersangkutan dengan permasalahan yang ingin diselesaikan. Aktivitas penelitian dilakukan secara terstruktur untuk mengelompokkan, mengerjakan, dan merumuskan data dengan mengaplikasikan cara/program tertentu untuk menemukan solusi dari permasalahan yang ada". Kata kunci yang digunakan dalam penelusuran in adalah model Pembelajaran Kooperatif Tipe jigsaw, hasil belajar, Pembelajaran Kooperatif, Tipe Jigsaw, Hasil Belajar, pembelajaran IPS, pembelajaran Matematika, pembelajaran IPA, pembelajaran PKN.

\section{HASIL DAN PEMBAHASAN}

mengetahui implementasi Model Pembelajaran Kooperatif Tipe Jigsaw yang dilakukan oleh guru sekolah dasar pada mata pelajaran IPS, Matematika, IPA, dan PKN. Berdasarkan hasil penelusuran didapatkan 8 artikel yang relevan dengan penelitian pnerapan Model Pembelajaran Kooperatif Tipe Jigsaw yang dapat meningkatkan hasil belajar siswa di sekolah dasar pada pembelajaran IPS, Matematika, IPA, dan PKN dapat dilihat pada Tabel 1.1 berikut:

Tabel 1.1 Analisis Sintesis Literatur

\begin{tabular}{lllllllrr}
\hline No & \multicolumn{3}{c}{ Author dan Judul } & \multicolumn{3}{c}{$\begin{array}{c}\text { Metode dan } \\
\text { Instrumen }\end{array}$} \\
\hline 1. & Pontoh, Hanafi, dkk. & (2016). Penerapan & Penelitian & Penerapan & Model \\
& Model & Pembelajaran & Jigsaw & Untuk & Tindakan & Pembelajaran & Kooperatif \\
& Meningkatkan & Hasil & Belajar & Ilmu & Kelas (PTK) & Tipe & Jigsaw & Dapat
\end{tabular}


Pengetahuan Sosial (IPS) Siswa Kelas V SD

Meningkatkan hasil belajar

Inpres Salabenda Kecamatan Bunta.

pada pembelajaran IPS.

2. Ismiyanti, Yulina. (2016). Peningkatan Penelitian

Penerapan

Model

Kualitas Pembelajaran IPS Melalui Tindakan

Pembelajaran

Kooperatif

Pembelajaran Kooperatif Tipe Jigsaw Kelas (PTK)

Tipe Jigsaw Berbasis Media

Berbasis Media Visual Di Kelas IV SDN 02

Visual dapat meningkatkan

Temulus.

kualitas pembelajaran IPS.

3. Nawawi. (2019). Peningkatan Hasil Belajar Penelitian

Penerapan

Model

Matematika Materi Pecahan Melalui Tindakan

Pembelajaran Kooperatif

Penerapan Model Pembelajaran Kooperatif Kelas (PTK) Tipe Jigsaw dapat

Tipe Jigsaw.

meningkatkan aktivitas dan hasil belajar siswa pada pelajaran Matematika.

4. Suparni, Nurul. (2017). Pengaruh Model Quasi Model Pembelajaran

Pembelajaran Kooperatif Tipe Jigsaw Experimental Kooperatif Tipe Jigsaw dapat

Terhadap Hasil Belajar Matematika Siswa meningkatkan hasil belajar

Kelas V SD Negeri 1 Metro Timur 2017.

5. Riadin, Agung dan Cici Liani Fitriani**. Penelitian Model Pembelajaran

(2018). Upaya Meningkatkan Hasil Belajar Tindakan Kooperatif Tipe Jigsaw dapat

Ipa Menggunakan Model Pembelajaran Kelas (PTK) meningkatkan hasil belajar

Kooperatif Tipe Jigsaw Dengan Berbantuan $\quad$ siswa pada pelajaran IPA.

Media Alat Peraga Konkret pada Peserta

Didik Kelas V SDN-4 Kasongan Baru

Tahun Pelajaran 2016/2017.

6. Asmara, Dedi. (2020). Penerapan Model Penelitian Metode jigsaw dapat Pembelajaran Kooperatif Tipe Jigsaw Tindakan meningkatkan prestasi belajar

Untuk Meningkatkan Hasil Belajar IPA Kelas (PTK) IPA pada siswa kelas VI.

Siswa.

7. Elyawati. (2018) Penerapan Model Penelitian Model pembelajaran

Pembeajaran Kooperatif Tipe Jigsaw Untuk Tindakan Kooperatif Tipe Jigsaw

Meningkatkan Hasil Belajar Pkn Siswa Kelas (PTK) efektif untuk meningkatkan

Kelas V Sd Negeri Cikijing III Kecamatan hasil belajar PKn.

Cikijing Kabupaten Majalengka. 
8. Dwijayani, Rizki dkk. (2018). Peningkatan Penelitian Model pembelajaran Tanggung Jawab Dan Hasil Belajar Kognitif Tindakan Kooperatif Tipe Jigsaw Siswa Kelas III SD Melalui Model Kelas (PTK) efektif untuk meningkatkan Pembelajaran Jigsaw Pada Mata Pelajaran hasil belajar PKn.

Pkn.

Hasil penelitian dan pembahasan yang dilakukan oleh Pontoh, Hanafi, dkk. (2016) mendapatkan hasil penelitian ini didapatkan ketuntasan belajar klasikal sebesar 86,84\% serta daya serap klasikal sebesar 73,8\% serta persentase nilai rata-rata sebesar 73,82\%. Maka dapat dikatakan bahwa tindakan yang dilakukan melalui penerapan model pembelajaran kooperatif tipe jigsaw dapat meningkatkan hasil belajar pada pembelajaran IPS di kelas V SD Inpres Salabenda Kecamatan Bunta Kabupaten Banggai.

Hasil penelitian dan pembahasan yang dilakukan oleh Ismiyanti (2016) mendapatkan persentase ketuntasan hasil belajar siswa siklus I sebesar 73,7\%, siklus II meningkat menjadi 78,9\%, dan siklus III mengalami peningkatan menjadi 92,1\%. Simpulan penelitian ini adalah penerapan model pembelajaran kooperatif tipe Jigsaw berbasis media visual dapat meningkatkan kualitas pembelajaran IPS meliputi keterampilan guru, aktivitas siswa, dan hasil belajar siswa kelas IV SDN 02 Temulus.

Hasil penelitian dan pembahasan yang dilakukan oleh Nawawi (2019) mendapatkan hasil ketuntasan belajar siswa secara klasikal meningkat menjadi $100 \%$ pada siklus II maupun dari segi nilai rata-rata hasil evaluasi mrngalami peningkatan sebesar $8,1 \%$. peningkatan tingkat aktivitas belajar siswa peningkatan sebesar 1,4 dengan kategori Aktif. dapat di simpulkan bahwa Penerapan Model Pembelajaran Kooperatif Tipe Jigsaw dapat meningkatkan aktivitas dan hasil belajar siswa pada materi Pecahan di SDN 5 Aikmel.

Hasil penelitian dan pembahasan yang dilakukan oleh Suparni (2017) mendapatkan hasil dapat dari perbedaan hasil belajar antara kelas kontrol dan kelas eksperimen. Nilai rata-rata posttest kelas kontrol adalah 65,57 sedangkan kelas eksperimen adalah 73,58. Begitu pula pada perbandingan nilai N-Gain kelas kontrol 0,34, sedangkan kelas eksperimen 0,51. Berdasarkan hasil perhitungan uji hipotesis menggunakan rumus t-test pooled varians diperoleh thitung $>$ ttabel $(2,65>2,00)$, selanjutnya perhitungan dengan program statistik SPSS 23 diperoleh nilai sig(2-tailed) 0,025, $(0,025<0,05)$ sehingga Ho ditolak. Dari perhitungan tersebut dapat diperoleh bahwa model pembelajaran kooperatif tipe jigsaw dapat mempengaruhi hasil belajar siswa sebesar 2,5\%.

Hasil penelitian dan pembahasan yang dilakukan oleh Agung (2018) mendapatkan hasil pada pra tindakan perolehan rata-rata peserta didik 57dengan ketuntasan klasikal 28\%. Setelah 
penerapan model kooperatif tipe jigsaw meningkat pada siklus I perolehan nilai rata-rata peserta didik 81 dengan ketuntasan klasikal 94\%. Ada peningkatan hasil belajar IPA dalam materi gaya gravitasi,gaya gesek dan gaya magnet dalam menggunakan model pembelajaran kooperatif tipe jigsaw dengan berbantuan alat peraga konkret padakelas V SDN-4 Kasongan baru. Peningkatan tersebut dapat dilihat dari hasil belajar peserta didik.

Hasil penelitian dan pembahasan yang dilakukan oleh Asmara (2020) diperoleh peningkatan nilai rata-rata kelas subjek penelitian naik dari nilai rata-rata pra siklus 74.16, siklus I 79.58 menjadi 87.08 pada siklus II dan PTK ini dianggap berhasil. Simpulan, berdasarkan hasil penelitian, metode jigsaw dapat meningkatkan prestasi belajar IPA pada siswa kelas VI materi ciri-ciri khusus makhluk hidup hewan di SD Negeri 06 Sialang Kecamatan Kapur IX Kabupaten Lima Puluh Kota.

Hasil penelitian dan pembahasan yang dilakukan oleh Elyawati (2018) berdasarkan data yang diperoleh dari hasil akhir tes 11 dapat dijelaskan bahwa pada siklus 11 ini hampir semua siswa nilainya sudah meningkat, dari 34 orang siswa kelas V 32 siswa (94.11\%) nilainya sudah tuntas dan 2 orang siswa belum tuntas $(5.88 \%)$. Nilai tertinggi yang dicapai 90 , dan nilai terendah 70 . Dapat disimpulkan bahwa penerapan model pembelajaran kooperatif dengan metode Jigsaw efektif untuk meningkatkan hasil belajar PKn siswa kelas V.

Hasil penelitian dan pembahasan yang dilakukan oleh Dwijayani (2018) didapatkan hasil Hasil belajar kognitif siswa ditunjukan oleh besarnya ketuntasan belajar pada pra siklus skor ratarata sebesar 63,04, siklus I meningkat menjadi 65,25, siklus II skor rata-rata menjadi 75,50. Adapun ketuntasan belajar pada pra siklus adalah 47\%, siklus I meningkat menjadi $60 \%$ dan pada siklus 2 meningkat menjadi 80\%. Sedangkan skor aksimum nimal yang diperoleh pada siklus I sebesar 30, siklus 2 meningkat ,menjadi 40, dan siklus II hanya 15 namun rata-rata kelas meningkat. Skor maksimum pada pra siklus adalah 100, siklus I 95 dan pada siklus II meningkat kembali menjadi 100. Berdasarkan hasil penelitian ini disarankan agar guru mata pelajaran PKn dapat menggunakan model pembelajaran koperatif tipe Jigsaw sebagai salah satu alternatif model pembelajaran.

\section{SIMPULAN}

Berdasarkan kajian studi literatur dan pembahasan yang telah dijelaskan pada uraian di atas, maka diperoleh kesimspulan bahwa penggunaan model pembelajaran Kooperatif Tipe Jigsaw efektif untuk meningkatkan hasil belajar siswa sekolah dasar pada mata pelajaran IPS, Matematika, IPA, dan PKN. 


\section{DAFTAR PUSTAKA}

Asmara, Dedi. (2020). Penerapan Model Pembelajaran Kooperatif Tipe Jigsaw Untuk Meningkatkan Hasil Belajar IPA Siswa. JOEAI (Journal of Education and Instruction) Volume 3, Nomor 1, Juni 2020 e-ISSN : 2614-8617 p-ISSN : 2620-7346. https://journal.ipm2kpe.or.id/index.php/JOEAI/article/view/1286

Dwijayani, Rizki, dkk. (2018). Peningkatan Tanggung Jawab dan Hasil Belajar Kognitif Siswa Kelas III SD Melalui Model Pembelajaran Jigsaw Pada Mata Pelajaran PKN. Jurnal KALAM CENDEKIA, Volume 6, Nomor 4.1, h16 - 23. https://core.ac.uk/download/pdf/296346578.pdf

Elyawati. (2018) Penerapan Model Pembeajaran Kooperatif Tife Jigsaw Untuk Meningkatkan Hasil Belajar PKN Siswa Kelas V SD Negeri Cikijing III Kecamatan Cikijing Kabupaten Majalengka. Jurnal: Jurnal Cakrawala Pendas Vol. 4 No.1 Edisi Januari 2018 e-ISSN: 25794442. http://www.jurnal.unma.ac.id/index.php/CP/article/view/714

Huda, Miftahul. (2014). Model-model Pengajaran dan Pembelajaran: Isu-isu Metodis dan Paradigmatis. Yogyakarta: Pustaka Pelajar

Ismiyanti, Yulina. (2016). Peningkatan Kualitas Pembelajaran IPS Melalui Pembelajaran Kooperatif Tipe Jigsaw Berbasis Media Visual di Kelas IV SDN 02 Temulus. Jurnal: Jurnal Ilmiah "PENDIDIKAN DASAR" Vol. III No. 1 Januari 2016. http://lppmunissula.com/jurnal.unissula.ac.id/index.php/pendas/article/download/724/603

Kristin, F. 2016. Analisis Model Pembelajaran Discovery Learning Dalam Meningkatkan Hasil Belajar Siswa SD. Jurnal Pendidikan Dasar Perkhasa, 2 (1). 26. Kristin, F. 2016. Efektivitas Model Pembelajaran Kooperatif Tipe STAD Ditinjau Dari Hasil Belajar IPS Siswa Kelas 4 SD. Scholaria: Jurnal Pendidikan dan Kebudayaan, 6 (2): 74-79.

Kristin, F. (2018). Meta-Analisis Pengaruh Model Pembelajaran Role Playing Terhadap Hasil Belajar IPS. Jurnal Refleksi Edukatika 8 (2) (2018) p-ISSN: 2087-9385 e-ISSN: 2528-696X Diakses di linkhttp://jurnal.umk.ac.id/index.php/RE

Melinda, Vina, dan Melva Zaini. (2020). Penerapan Model Project Based Learning untuk Meningkatkan Kemampuan Komunikasi Matematis Siswa Sekolah Dasar (Studi Literatur). Jurnal Pendidikan Tembusai: Volume 4 Nomor 2 Tahun 2020 SSN: 2614-6754 (print) ISSN: 2614-3097(online) Halaman 1526-1539

Nurdyansyah dan Eni Fariyatul Fahyuni. (2016). Inovasi Model Pembelajaran Sesuai Kurikulum 2013. Sidoarjo: Nizamia Learning Center

Nawawi. (2019). Peningkatan Hasil Belajar Matematika Materi Pecahan Melalui Penerapan Model Pembelajaran Kooperatif Tipe Jigsaw. Jurnal: PENSA : Jurnal Pendidikan dan Ilmu Sosial Volume 1, Nomor 1, Agustus 2019; 83-95. https://ejournal.stitpn.ac.id/index.php/pensa

Pontoh, Hanafi, dkk. (2016). Penerapan Model Pembelajaran Jigsaw Untuk Meningkatkan Hasil Belajar Ilmu Pengetahuan Sosial (IPS) Siswa Kelas V SD Inpres Salabenda Kecamatan Bunta. Jurnal: Jurnal Kreatif Tadulako Online Vol. 4 No. 11. ISSN 2354-614X. https://media.neliti.com/media/publications/120966-ID-penerapan-model pembelajaranjigsaw-untu.pdf

Rahman. (2019). Model Mengaiar \& Bahan Pembelaiaran. Sumedang: Alqaprint Jatinangor 
Riadin, Agung dan Cici Liani Fitriani. (2018). Upaya Meningkatkan Hasil Belajar Ipa Menggunakan Model Pembelajaran Kooperatif Tipe Jigsaw dengan Berbantuan Media Alat Peraga Konkret Pada Peserta Didik Kelas V SDN-4 Kasongan Baru Tahun Pelajaran 2016/2017. (2018). Jurnal: Pedagogik Jurnal Pendidikan, Oktober 2018, Volume 13 No 2 (1-5). http://journal.umpalangkaraya.ac.id/index.php/pedagogik/article/view/861

Suparni, Nurul. (2017). Pengaruh Model Pembelajaran Kooperatif Tipe Jigsaw Terhadap Hasil Belajar Matematika Siswa Kelas V SD Negeri 1 Metro Timur. Skripsi: FAKULTAS KEGURUAN DAN ILMU PENDIDIKAN UNIVERSITAS LAMPUNG BANDAR LAMPUNG http:/ / digilib.unila.ac.id/26829/2/SKRIPSI\%20TANPA\%20BAB\%20PEMBAHASAN.p df 